Available online at http://jddtonline.info RESEARCH ARTICLE

\title{
THE EFFECT OF PLASTICIZER CONCENTRATION ON POLYMERIC TRANSDERMAL PATCH
}

\author{
*Singh Anita ${ }^{1}$, Vijaykumar M. ${ }^{2}$ \\ ${ }^{1}$ Bhagwant University, Department of Pharmaceutical science, Ajmer (Raj.) INDIA \\ ${ }^{2}$ National Botanical Research Institute, Lucknow (Uttar Pradesh) INDIA
}

*Corresponding Author's Email- anita2001@ rediffmail.com

\begin{abstract}
An effort was made to formulate drug free transdermal patches by using different polymers like ethyl cellulose, poly vinyl pyrrolidone and eudragit. Four groups of twelve formulations of drug free transdermal patches were prepared by solvent evaporation technique in which each group have different plasticizer concentration and evaluated for flatness, tensile strength, folding endurance, moisture content, Water vapor transmission rate (WVTR), percent elongation.

The tensile strength and folding endurance of the patches prepared with $20 \%$ Di-n-butylphthalate as plasticizer was high compared to patches prepared by $10 \%$ and $15 \%$ Di-n-butylphthalate. The result of $20 \%$ plasticizer indicated that the patches would not break and would maintain their integrity with general skin folding when used. All the formulations show $100 \%$ flatness. The WVTR was not significantly affected by varying the concentration of plasticizer (Di-n-butylphthalate). At concentration of $25 \%$ of plasticizer the tensile strength and percent elongation not shows significant result due to soft and sticky formulation. On the basis of above observations we can easily concluded that the Di-n-butylphthalate at concentration $20 \%$ of polymers used as plasticizer for further developmental studies.
\end{abstract}

Key words: Di-n-butylphthalate, plasticizer, ethyl cellulose, tensile strength, transdermal patch.

\section{INTRODUCTION}

Transdermal drug delivery systems, known as patches, are dosage forms designed to deliver a therapeutically effective amount of drug across a patient's skin in a predetermined time and controlled rate $e^{1,2}$. There are three critical considerations in the selection of a transdermal drug delivery system: adhesion to skin, compatibility with skin, and physical or chemical stability of total formulation and components ${ }^{3}$. The choice and design of polymers, adhesives, penetration enhancers and plasticizers in transdermal patches are also critical because they have a strong effect on drug release, permeability, stability, elasticity, and wearing properties of transdermal drug delivery systems ${ }^{4}$. The use of plasticizers in transdermal drug delivery systems are the improvement of film forming properties and the appearance of the film, decreasing the glass transition temperature of the polymer, preventing film cracking, increasing film flexibility and obtaining desirable mechanical properties ${ }^{5}$. Plasticizers are low molecular weight resins or liquids, which cause a reduction in polymerpolymer chain secondary bonding, forming secondary bonds with the polymer chains instead ${ }^{6}$. The main reasons of adding plasticizers to polymers, improving flexibility and process ability are counted ${ }^{7,8}$. By adding plasticizer to a polymeric material, elongation at break, toughness and flexibility are expected to increase, on the other hand tensile stress, hardness, are expected to decrease ${ }^{9}$.

In the present study drug free patches of different polymers were formulated and evaluated. The effect of different concentrations of plasticizer viz. $10 \%, 15 \%$, $20 \&$ and $25 \%$ on physicochemical properties of drug free patches was also studied.

\section{MATERIAL AND METHOD}

Di-n-butylphthalate (Loba Chemie), chloroform, methanol (S. D. Fine Chem. Ltd.), Ethyl cellulose (Kemphasol Ltd.). Poly vinyl pyrrolidone (Wockhardt Ltd.), aluminum foil purchased from local market. All other chemicals used were of analytical grade.

The drug free transdermal patch was fabricated by solvent evaporation technique using Mercury substrate method. The different polymers were weighed in same ratios and dissolve in $5 \mathrm{ml}$ of solvents. The plasticizer (Di-n-butylphthalate) was added at different concentration and stirred to get clear solution. The polymeric solution was then poured slowly into a glass ring on the mercury surface. The solvent was allowed to evaporate at $25^{\circ} \mathrm{C}$ for $24 \mathrm{~h}$. The films were stored in desiccator until further evaluation. The composition of drug free transdermal patches is shown in Table 1.

\section{Evaluation of the films/patches}

The fabricated patch was subjected to physicochemical evaluation by using following tests.

\section{Folding Endurance}

The folding endurance is defined as the number of folds required to break any polymeric patch ${ }^{10}$. This was performed as a primary test to asses the strength and flexibility of film. This was determined by repeatedly folding the film at the same place until it broke. The number of time the film could be folded at the same place without breaking/cracking was taken as value of folding endurance ${ }^{11,12}$. 
Table 1: Formulation of drug free transdermal patches

\begin{tabular}{|c|c|c|c|c|c|c|c|c|c|c|c|c|c|}
\hline Class of ingredients & Ingredients & F1 & F2 & F3 & F4 & F5 & F6 & F7 & F8 & F9 & F10 & F11 & F12 \\
\hline Plasticizer (mg) & Di-n-butylphthalate & 10 & 10 & 10 & 15 & 15 & 15 & 20 & 20 & 20 & 25 & 25 & 25 \\
\hline \multirow{2}{*}{$\begin{array}{c}\text { Solvents } \\
(\mathbf{m l})\end{array}$} & Chloroform & 4 & 4 & 4 & 4 & 4 & 4 & 4 & 4 & 4 & 4 & 4 & 4 \\
\hline & Methanol & 1 & 1 & 1 & 1 & 1 & 1 & 1 & 1 & 1 & 1 & 1 & 1 \\
\hline \multirow{4}{*}{$\begin{array}{c}\text { Polymers } \\
\text { Ratio } \\
(1: 1)\end{array}$} & ERS-100 & -- & 1 & -- & -- & 1 & $\overline{--}$ & -- & 1 & -- & -- & 1 & - \\
\hline & Poly vinyl pyrrolidone & 1 & -- & 1 & 1 & -- & 1 & 1 & -- & 1 & 1 & -- & 1 \\
\hline & Ethyl cellulose & -- & -- & 1 & -- & -- & 1 & -- & -- & 1 & -- & -- & 1 \\
\hline & ERL-100 & 1 & 1 & -- & 1 & 1 & -- & 1 & 1 & -- & 1 & 1 & -- \\
\hline
\end{tabular}

\section{Flatness}

Longitudinal strips were cut out from the prepared medicated patches and the length of each strip was measured and then the variation in the lengths due to the non-uniformity in flatness was measured. Flatness was calculated by measuring constriction of strips and a zero percent constriction was considered to be equal to a hundred percent flatness.

$$
\text { Constriction }(\%)=\left(\mathrm{L}_{1}-\mathrm{L}_{2}\right) / \mathrm{L}_{1} \times 100 \text {, }
$$

Where $L_{1}$ and $L_{2}$ are the initial length and final length of each strip respectively ${ }^{13,14}$

\section{Moisture content}

The film was weighed and kept in a desiccator containing calcium chloride at $40^{\circ} \mathrm{C}$ for at least $24 \mathrm{~h}$. The percentage moisture content was calculated as the difference between initial weight and final constant weight and reported with respect to the initial weight ${ }^{15}$.

\section{Moisture Uptake}

The films were weighed accurately and placed in desiccator containing $100 \mathrm{ml}$ saturated solution of aluminum chloride, which maintains $79.5 \%$ RH. After 3 days, the films were taken out and weighed. The percentage moisture uptake was calculated as difference between final and initial weight with respect to initial weight $^{14}$.

\section{Water vapor transmission rate (WVTR)}

Glass vials of equal diameter used as transmission cells. These transmission cells were washed thoroughly and dried in an oven. About $1 \mathrm{gm}$ of anhydrous calcium chloride was placed in the cells and respective polymer film was fixed over the brim. The cells were accurately weighed and kept in a closed desiccator containing saturated solution of potassium chloride to maintain $\mathrm{RH}$ $84 \%$. The cells were taken out and weighed after 6,12 , 24, 36, 48 and $72 \mathrm{~h}$ of storage. The amount of water vapor transmitted was calculated by using following formula and expressed as the number of grams of moisture gained $/ \mathrm{h} / \mathrm{cm}^{2}$.

Water vapor transmission rate

$$
=\frac{\text { final weight }- \text { initial weight }}{\text { Time } \times \text { Area }}
$$

\section{Tensile strength}

Mechanical properties of the polymeric patches were conveniently determined by measuring their tensile strength $^{16}$. The tensile strength of the patches was determined by using a tensile strength instrument. Tensile strength is the maximum stress applied to a point at which the specimen breaks, and can be computed from the applied load at rupture and the elongation of the patch as described from the following equation.

$$
\text { T.S. }=\text { Break Force/ a. b }(1+\Delta \mathrm{L} / \mathrm{L})
$$

Where $a, b$ and $L$ are width, thickness and length of the strip respectively.

$\Delta \mathrm{L}$ is the elongation of patch at break point.

Break force $=$ Weight required to break the patch $(\mathrm{Kg} .)^{17}$

Tensile strength was calculated as the weight required for breaking the film $\left(\mathrm{kg} / \mathrm{cm}^{2}\right)$.

\section{Percent elongation}

It was calculated from the elongation (length) at the moment of rupture of the film divided by the initial gauge length of the film and multiplying by 100 . An instrument and procedure was similar to that used for tensile strength ${ }^{18}$.

\section{Percent elongation at break $=\mathrm{Lb}-\mathrm{Lo} / \mathrm{Lo} X 100$}

$\mathrm{Lb}=$ Length of the specimen in $\mathrm{cm}$ where it breaks.

$$
\text { Lo }=\text { Original length of specimen } \text {. }
$$


Table 2: Evaluation of drug free transdermal patches

\begin{tabular}{|c|c|c|c|c|c|c|}
\hline \multicolumn{2}{|c|}{$\begin{array}{c}\text { Group/ } \\
\text { Formulations }\end{array}$} & $\begin{array}{c}\text { Folding } \\
\text { Endurance }\end{array}$ & $\begin{array}{c}\text { Water vapor } \\
\text { transmission rate } \\
\left(\mathrm{gm} / \mathrm{h} / \mathrm{cm}^{2} \times 10^{-4}\right)\end{array}$ & $\begin{array}{c}\text { Tensile } \\
\text { Strength } \\
\left(\mathrm{kg} / \mathrm{cm}^{2}\right)\end{array}$ & $\begin{array}{c}\text { Percent } \\
\text { Elongation }\end{array}$ & Flatness \\
\hline \multirow{3}{*}{ Group-A } & F-1 & 06 Folds & 3.70 & 2.2 & $11 \%$ & $100 \%$ \\
\hline & F-2 & 10 Folds & 3.40 & 3.5 & $13 \%$ & $100 \%$ \\
\hline & F-3 & 08 Folds & 2.25 & 2.8 & $10 \%$ & $100 \%$ \\
\hline \multirow{3}{*}{ Group-B } & F-4 & 09 Folds & 4.00 & 3.1 & $14 \%$ & $100 \%$ \\
\hline & F-5 & 13 Folds & 3.60 & 4.2 & $15 \%$ & $100 \%$ \\
\hline & F-6 & 10 Folds & 2.40 & 3.2 & $12 \%$ & $100 \%$ \\
\hline \multirow{3}{*}{ Group-C } & F-7 & 13 Folds & 4.3 & 4.5 & $20 \%$ & $100 \%$ \\
\hline & F-8 & 18 Folds & 3.87 & 5.8 & $26 \%$ & $100 \%$ \\
\hline & F-9 & 12 Folds & 2.60 & 4.1 & $15 \%$ & $100 \%$ \\
\hline \multirow{3}{*}{ Group-D } & F-10 & 20 Folds & No & No & No & $100 \%$ \\
\hline & F-11 & 21 Folds & No & No & No & $100 \%$ \\
\hline & F-12 & 16 Folds & 3.20 & 4.3 & $17 \%$ & $100 \%$ \\
\hline
\end{tabular}

\section{RESULT AND DISCUSSION}

Transdermal drug delivery system is one of the promising alternatives to oral dosage forms especially for drugs that are subjected to first pass metabolism. Evaluation of free patches has proved a popular means of assessing the properties of polymeric patches. The use of mercury substrate method for the preparation yielded transparent, smooth and uniform patches. The drug free patches of different polymers were prepared by solvent evaporation technique employing mercury as a substrate to explore their feasibility for transdermal application.

The formulations were evaluated (Table-2) for tensile strength, WVTR, folding endurance, Water vapor transmission rate and percent elongation properties.
Flatness studies were performed to assess the same. 100 $\%$ flatness of all the formulation indicates no amount of constriction in formulated transdermal patches. Thus this could better maintain a smooth surface when applied onto the skin.

The folding endurance measures the ability of patch to withstand rupture. The patch prepared by $20 \%$ concentration of plasticizer Group-D (F-10, F-11, F-12) having very large folding endurance as compare to the films prepared by $10 \%$ concentration of plasticizer Group-A (F-1, F-2, F-3) with different polymers combination (Figure 1). The result of $20 \%$ plasticizer indicated that the patches would not break and would maintain their integrity with general skin folding when used.

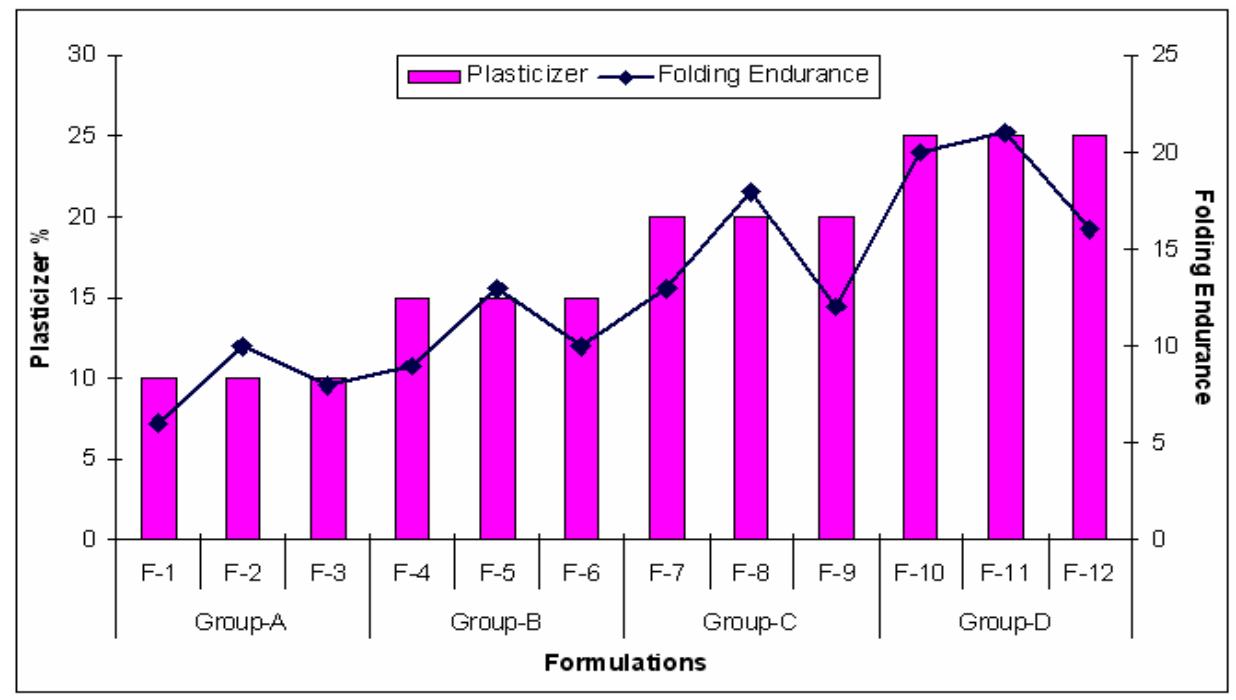

Figure 1: Performance of folding endurance test of drug free transdermal patch

The WVTR was not significantly affected by varying the concentration of plasticizer (Di-n-butylphthalate) as shown in the table 2 .

When we focus on the tensile strength and percent elongation value of the fabricated formulations the height of response increases as increases the concentration of plasticizer (Di-n-butylphthalate) but when the concentration of plasticizer increases $25 \%$, Group-D (F-
$10 \&$ F-11) the no any satisfactory result found due to soft and sticky film (Figure 2). On 20\% concentration of plasticizer form stable film (F-7, F-8, F-9). The difference between Group-A and Group-B in percent elongation is not very large (10\% to $15 \%$ only) but at same polymer ratio and different plasticizer concentration the Group-C (F-7, F-8, F-9) have very high percent elongation. 


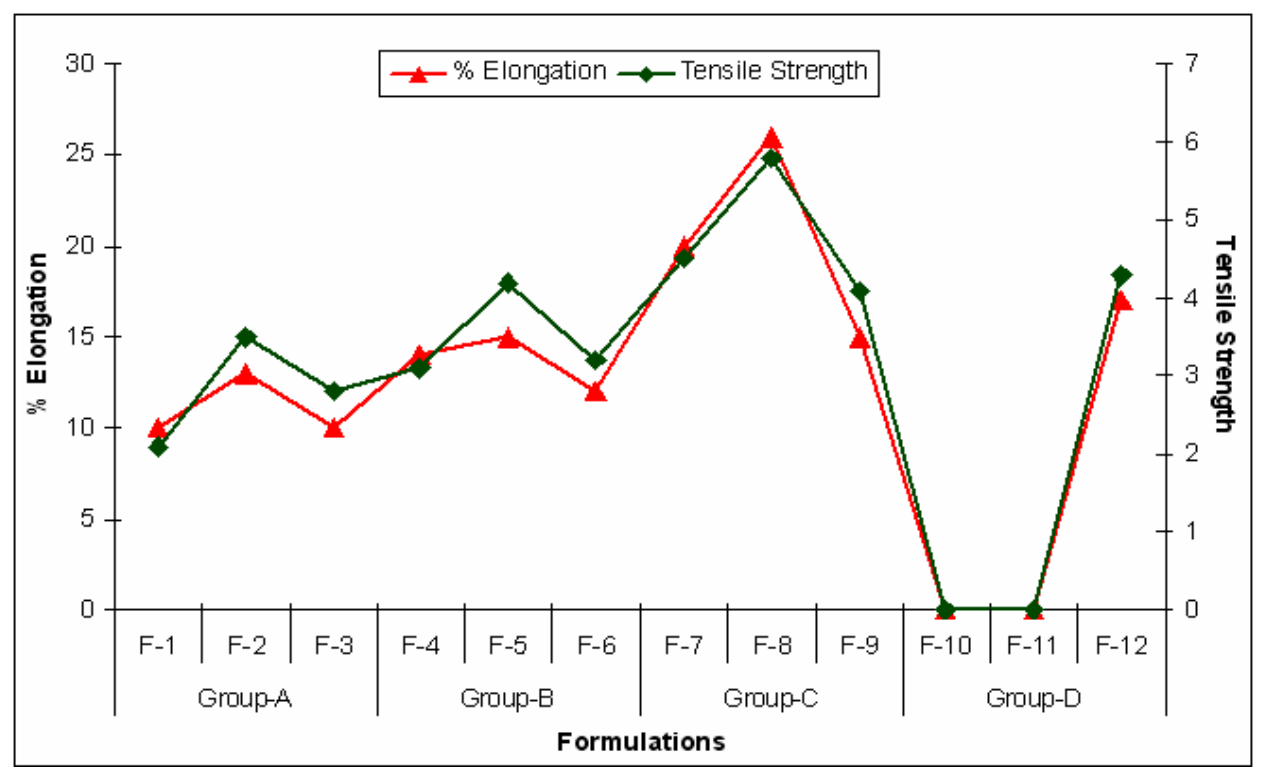

Figure 2: Performance of tensile strength and percent elongation test of drug free transdermal patch

\section{CONCLUSION}

Hence from above study it can be concluded that, the effect of concentration of plasticizer on the formulation is very important for developing a good and stable formulation. Here the $20 \% \mathrm{w} / \mathrm{w}$ concentration of Di-nbutylphthalate was the optimum concentration which

\section{REFERENCE}

1. Aulton M.E., Aulton's Pharmaceutics: The Design and Manufacture of Medicines. 3rd edithon, 2007, 565-597.

2. Vasil'ev A.E.; Krasnyuk, I.I. Tokhmakhchi V.N., Transdermal Therapeutic Systems for Controlled Drug Release. Pharm. Chem. J., 2001, 35, 613-626.

3. Walters K.A., Brain K.R., Dermatological Formulation and Transdermal Systems. In: Dermatological and Transdermal Formulations. Walters KA Edition, 2002, 319-400,

4. Quan D., Passive Transdermal Drug Delivery Systems (TDDS): Challenges and Potential. Transdermal Magazine, 2011, 3, 6-12.

5. Wypch G., Handbook of Plasticizers, Chem Tec, 2004, 437440.

6. Rajan R., Sheba R.N.D,. Kajal, G., Sanjoy K. D., Jasmina K., Design and In Vitro Evaluation of Chlorpheniramine Maleate From Different Eudragit Based Matrix Patches: Effect of Plasticizer and Chemical Enhancers. ARS Pharmaceutica, 2010, 50, 4,177-194.

7. Harper C.A. Handbook of Plastic Technologies, the Complete Guide to Properties and Performance, Mc Graw-Hill Handbooks, 2006

8. Höfer R., Hinrichs, K., Additives for the Manufacture and Processing of Polymers, In: Polymers-Opportunities and Risks II: Sustainability, Product Design and Processing, Eyerer, P. Weller, M., Hübner C., Agnelli J.A., Edition, 2010, 120.

9. Rahman M., Brazel C.S., The Plasticizer Market: An Assessment of Traditional Plasticizers and Research Trends to Meet New Challenges. Progress in Polymer Science, 2004, 29, 1223-1248.

10. Banweer J, Pandey S, Pathak, AK. Formulation, Optimization and Evaluation of Matrix type Transdermal system of forms the films with good strength, flexibility and appearance. When we increase the concentration it effects on the stability of formulation. For further developmental studies Di-n-butylphthalate was incorporated as a plasticizer at a concentration of $20 \%$ w/w of polymers.
Lisinopril dihydrate using permeation enhancers. Journal of Pharmacy Research. 2008, 1,1, 16-22.

11. Patel NA, Patel NJ, Patel RP. Design and Evaluation of Transdermal Drug Delivery System for Curcumin as an AntiInflammatory Drug. Drug Dev Ind Pharm., 2009, 35, 234-242.1

12. Kusum D. V., Saisivam S., Maria G. R., Deepti P. U., Design and evaluation of matrix diffusion controlled transdermal patches of Verapamil hydrochloride, Drug Dev. Ind. Pharm., 2003, 29, 5, 495-503.

13. Ubaidulla U, Reddy MV, Ruckmani K, Ahmad FJ, Khar RK. Transdermal therapeutic system of Carvedilol: Effect of hydrophilic and hydrophobic matrix on in vitro and in vivo characteristics. AAPS Pharm Sci Tech. 2007, 8, 1, 1-8.

14. Mutalik S., Udupa N., Glibenclamide transdermal patches: Physiochemical, pharmacodynamic and pharmacokinetic evaluation, J. pharm. Sci., 2004, 91, 1577-1594.

15. Gupta R., Mukharjee B., Development and in-vitro evaluation of Diltiazem hydrochloride transdermal patches based on povidone - ethyl cellulose matrices, Drug Dev.Ind.Pharm., 2003, 1, 1-7.

16. Samanta MK, Dube R, Suresh B. Transdermal drug delivery system of Haloperidol to overcome self induced extrapyramidal syndrome. Drug Dev Ind Pharm. 2003, 29, 4, 405-415.

17. Ahmed MG, Charyulu RN, Harish NM, Prabhu P. Formulation and in-vitro evaluation of chitosan films containing Tetracycline for the treatment of periodontitis. Asian journal of Pharmaceutics. 2009, 113-119.

18. Kulkarni R. V., Mutalik S., Hiremath D., Effect of plasticizers on the permeability and mechanical properties of eudragit films for transdermal application, Indian J. Pharm. Sci., 2002, 64, 1, 28-31. 